\title{
MANUEL SAN JUAN DE SANTA CRUZ: GOBERNADOR, LATIFUNDISTA Y CAPITÁN DE GUERRA DE LA FRONTERA NORTE
}

\author{
POR
}

SALVADOR ÁLVAREZ

El Colegio de Michoacán, México

\begin{abstract}
Por medio del análisis de los papeles personales de un poderoso hacendado y hombre de armas, combinado con el estudio del funcionamiento de un gran latifundio, en este caso, Manuel de San Juan de Santa Cruz y la hacienda de Encinillas, vemos cómo la conformación de estos grandes dominios territoriales no puede explicarse solamente como producto de la «necesidad de prestigio» o de una simple «inclinación» hacia un «modo de vida aristocrático» por parte de sus propietarios.
\end{abstract}

Palabras Clave: Latifundio, indios, guerra, Nueva Vizcaya, hacienda.

\section{De Manila a Chinuahua}

Manuel San Juan de Santa Cruz y de Talledo fue el gobernador número cuarenta y tres que tuvo la Nueva Vizcaya desde su fundación en 1562. Al igual que la mayoría de sus antecesores, en el momento de asumir el puesto, Manuel de San Juan desconocía el norte novohispano y, de hecho, su nombramiento como máxima autoridad de aquella lejana provincia le llegó de manera casi circunstancial. Y es que no fueron ni la Corona ni el Consejo de Indias los que lo eligieron, sino que la decisión la tomó un particular llamado Domingo Ramírez de Arellano. Este era hermano y albacea testamentario de José Ramírez de Arellano, quien, en 1710, siendo aún castellano de San Juan de Ulúa, había comprado el puesto de gobernador de la Nueva Vizcaya. Sin embargo, dado que murió antes de iniciar el periodo pactado, su albacea, haciendo uso del derecho que el propio privilegio le otorgaba, eligió a Manuel San Juan de Santa Cruz como sustituto en el cargo: corría el año de $1714^{1}$.

\footnotetext{
1 Porras Muñoz, 1980: 86.
} 
Los hermanos San Juan de Santa Cruz eran originarios de Barrieta, consejo de Sopuerta, en las Encartaciones de Vizcaya, en donde Manuel fue bautizado el 6 de agosto de 1679. Francisco, el primogénito de la familia, al menos diez años mayor que él, abrazó desde muy joven el oficio de las armas y para 1692 se hallaba como soldado mosquetero en la armada de Barlovento. En 1698, encontramos ya a los dos sirviendo juntos en el presidio real de Santo Domingo y juntos igualmente partieron para las Filipinas con la Compañía de Infantería Española, Artilleros y Gente de Mar, que salió ese año de Acapulco en auxilio del real campo de Manila ${ }^{2}$. Allá estuvieron probablemente hasta 1702, cuando los encontramos finalmente en la Nueva España.

Para esa época, Manuel de San Juan bien hubiera podido ser catalogado ya como un hombre del comercio con Filipinas. Todo indica que regresó de Oriente con un buen caudal, pues se asentó en México, en donde puso una casa, y es al parecer durante esos años cuando adquirió sus haciendas de San Pedro Cuamantla y San Nicolás de Lanzarote, ambas en la jurisdicción de Cuautitlán ${ }^{3}$. Además, en 1711, logró hacerse caballero de Santiago ${ }^{4}$. En 1712, enviudó de su primera esposa, Petra Teresa de Sarasa y Rojas (de la que sabemos poco), y se unió en nuevas nupcias con Claudia Gallo de Pardiñas, hija del sargento mayor Miguel Gallo, quien desde 1680 venía fungiendo como castellano del castillo de San Diego de Acapulco 5 . Para la época de este matrimonio, Gallo era dueño de varias haciendas cercanas al camino de México a Acapulco, entre ellas las de San Juan de los Llanos y San Marcos, que proveían de bastimentos, aperos y animales a los convoyes de Acapulco. Su triple situación de guardián del tráfico marítimo, proveedor de mercaderes, y subrepticiamente, mercader él mismo $^{6}$, permitió a Gallo introducirse en la gran sociedad novohispana e instalarse a vivir en la ciudad de México, en donde fue dueño de una suntuosa casa ${ }^{7}$. Su pasado como soldado y negociante y los lazos familiares que se había tejido, habían hecho de Manuel de San Juan un hombre

2 Relación de Méritos y Servicios de Francisco San Juan Santa Cruz, 1737, Archivo General de Indias, Sevilla (AGI), Indiferente General, legajo 147, exp. 87.

3 Concurso de bienes de Manuel San Juan de Santa Cruz. Despacho para que se embarguen sus bienes, Archivo General de la Nación, México (AGN), Tierras, legajo 375, exp 3, 1750.

4 Labayru y Goicoechea, 1967: 57.

5 Martínez de Cosío, 1946: 179.

6 Papeles por los que constan las cantidades cobradas de las condenaciones hechas en las pesquisas que se hizo contra Don Miguel Gallo, de la real fortaleza de San Diego de Acapulco, sus tenientes oficiales reales y otros ministros; y sobre el embarque de pesos sin permiso ni registro, 1711-1712, AGI, Contaduría, legajo 184, n. ${ }^{\circ} 6$.

7 Franco Glorinela, 1994-1995: 310. 
de caudales. Además de lo que tuvo que entregar a Domingo Ramírez de Arellano por la transferencia de la merced real originaria (al menos los 14.000 pesos del precio), Manuel debió todavía servir a la Corona con otros 23.000 pesos antes de que el virrey Duque de Linares diera el visto bueno a su nombramiento, y además se sabe que llevó consigo a Durango varias decenas de miles de pesos.

Desde hacía ya algunas décadas, la Nueva Vizcaya vivía un periodo de profundas transformaciones, marcadas, sobre todo, por una fuerte expansión territorial. Durante un buen tiempo, la fama del real de minas del Parral (fundado en 1631) había operado como un imán para inmigrantes, lo que hizo posible que la provincia de Santa Bárbara, en donde se hallaba enclavado, se convirtiera en una segunda zona de colonización española estable y permanente en la Nueva Vizcaya, junto con Durango y su vecindad. Sin embargo, la bonanza minera no duró mucho. Para la década de 1660, la disminución en los rendimientos de los minerales y las crecientes dificultades para el traslado de mano de obra forzada indígena condujeron a la minería local, no a una borrasca, sino a una verdadera catástrofe. Tan fue así que, para 1670, las minas del Parral se hallaban prácticamente paralizadas. Sin embargo, no ocurría lo mismo con la región circundante, en donde las haciendas agrícolas, especialmente las del valle de San Bartolomé, vivían un periodo de crecimiento demográfico y agrícola, y comenzaron también a expandirse territorialmente ${ }^{8}$.

Hasta principios de la década de 1660, la corriente del río Conchos había permanecido como una virtual frontera para el poblamiento español en la provincia. Más allá, hacia el norte, el primer establecimiento español era Santa $\mathrm{Fe}$ del Nuevo México, situada a casi mil kilómetros a vuelo de pájaro: nada más existía en el camino. Esto se rompió gracias, precisamente, a la expansión de las haciendas agrícolas de San Bartolomé, las cuales, no solamente crecieron territorialmente, sino que comenzaron también a multiplicarse ${ }^{9}$. Se abrió entonces un periodo durante el cual vemos a hacendados y encomenderos de esa región partir acompañados de sus allegados y familiares españoles, sus indios y sirvientes, sus armas, caballos y aperos, hacia la región allende el río Conchos, en donde empezaron a abrir tierras, a edificar casas-fuertes y a «poblar» estancias de ganado. Fruto de ese movimiento fue la fundación de un número importante de nuevas haciendas, muchas de ellas de gran tamaño (ver carta n..$^{\circ} 1$ ).

Con este «poblamiento latifundista», aparecieron también las primeras misiones y reducciones permanentes, tanto a lo largo del propio río Conchos y

8 Álvarez, en prensa.

9 Álvarez Salvador, 2000: 73-108. 


\section{Carta no. 1 \\ El poblamiento latifundista \\ en el norte de la Nueva Vizcaya \\ 1680-1720}

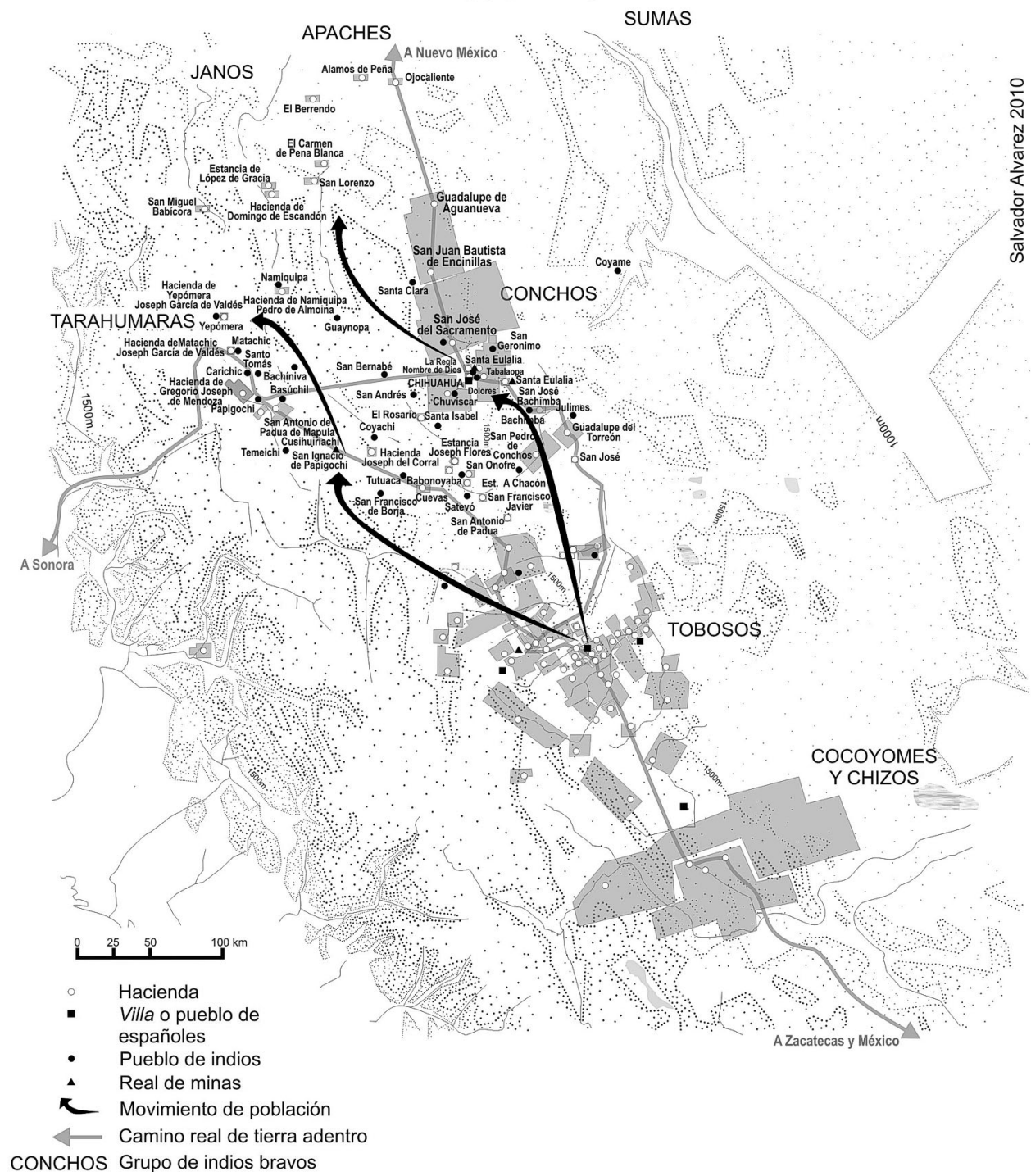

sus afluentes, como en la región tarahumara del río Papigochi y, un poco más al sur, en la de Cusihuiriachi, y ello favoreció a su vez el abasto de mano de obra para los establecimientos coloniales. Desde principios de la década de 
1680, se levantan allí estancias de españoles, algunas de las cuales terminaron rápidamente transformadas en haciendas, como las de San Ignacio de Papigochi, Pedernales y otras más. A su vez, ello permitió la apertura de los primeros centros mineros de importancia al norte del de Parral. El primero de ellos fue Coyachi, fundado en 1683, y poco después, en 1686, el de Cusihuiriachi, el cual en poco tiempo alcanzaría una gran celebridad por la riqueza de sus minerales. Se sabe, por ejemplo, que para 1688 había en Cusihuiriachi un centenar de mineros trabajando allí y aproximadamente la mitad en Coyachi y, en 1700, eran ya doscientos los mineros que laboraban en el primero. Mientras tanto, un proceso muy semejante se daba en la región de Chihuahua, situada sobre uno de los afluentes principales del bajo río Conchos, el Chuviscar. Allí se instalaron, desde la década de 1670, hacendados poderosos del valle de San Bartolomé, entre ellos Domingo de Apresa Falcón, quien fundó su hacienda de Santo Domingo de Tabalaopa muy cerca de lo que sería después Chihuahua. Un par de años más tarde, un sobrino suyo, Benito Pérez de Rivera, asentó, a su vez, un poco más al norte, la hacienda de San Juan de las Encinillas: una heredad que, como veremos más adelante, estaría íntimamente ligada con la vida de Manuel San Juan de Santa Cruz.

Durante las dos últimas décadas del siglo XVII, este movimiento expansivo prosiguió sin pausa, de manera que, para los inicios de la siguiente centuria, Cusihuiriachi era ya un real de minas plenamente consolidado, mientras que Chihuahua se había convertido en una región enteramente dominada por gruesas haciendas agrícolas (ver la carta $\mathrm{n}^{\mathrm{o}}$ 1) y en donde muy pronto la explotación de minerales comenzó también a desarrollarse. En 1707, se fundó lo que fue el primer centro minero de importancia en esa región: el de Santa Eulalia de Mérida, y dos años más tarde surgió otro más, llamado San Francisco de Cuéllar. Vemos entonces cómo, en el momento en que Manuel de San Juan asumía el gobierno de la Nueva Vizcaya, todo este complicado proceso de expansión territorial, migración, apertura de tierras y minas, acompañado todo ello de violentos desplazamientos de grupos de indígenas, se hallaba en pleno desarrollo. Nada de extraño tuvo entonces que el nuevo gobernador dejase la sede oficial de su gobernación, Durango, para apersonarse en ese lejano confín.

\section{El Capitán General de la Nueva VizCAya}

La presencia de Manuel de San Juan en la zona de Chihuahua se hacía también necesaria por la recepción de una real cédula, fechada en Madrid en 1702, que ordenaba el establecimiento de una nueva villa en esa región, la cual ya se 
disponía que llevara el nombre de San Felipe. En vista de esa futura fundación a su cargo ahora y dada la importancia demográfica que cobraba la zona, decidió fijar allí su residencia permanente. Pero, a pesar del progreso del poblamiento colonial, la situación con los indios seguía siendo delicada. Estos no se habían pacificado en realidad, sino que los españoles, siendo más numerosos ahora y estando mejor implantados en los nuevos territorios, simplemente habían logrado resistir más fácilmente los embates de los indios bravos y someterlos así a una cierta obediencia. Pero la guerra como tal no se detuvo; por el contrario, se intensificó y modificó sus patrones. Antiguamente, a los nativos de las regiones relativamente alejadas, les había bastado con desplazarse y mantenerse lejos de los españoles, para evitar, en alguna medida, su reducción forzada. Podría decirse, incluso, que hasta mediados del siglo XVII, los episodios más sangrientos protagonizados por los indios bravos en contra de los españoles en la Nueva Vizcaya corrieron casi siempre a cargo de aborígenes asentados por la fuerza en los establecimientos coloniales, como sucedió en repetidas ocasiones con los tobosos, por ejemplo ${ }^{10}$. En las tierras no controladas, en cambio, la hostilidad de los indios se reducía, generalmente, al asalto de algún convoy de carros, o de alguna partida de cazadores de cautivos, al martirio de algún irreflexivo misionero que se aventurara por sus territorios y a la realización de esporádicas incursiones en las zonas de poblamiento colonial sólido, en busca de granos, ganado y, sobre todo, caballos. Con la expansión territorial española, en cambio, los indígenas tuvieron a los colonizadores asentados allí, a unos cuantos kilómetros de sus rancherías, presionándolos cada vez más para que se congregaran en misiones y se sometieran al repartimiento y demás servicios personales, o bien incursionando con mucha mayor fuerza en busca de cautivos.

Todo lo anterior propició que indios antiguamente poco activos en la guerra, de pronto comenzaran a aparecer como enemigos temibles, dedicados ahora con mayor ahínco al asalto de conductas y, lo que era peor, al saqueo de las haciendas y ranchos limítrofes con sus territorios, robando ganado y caballos. Sucedió en las llanuras orientales y en el Bolsón de Mapimí, en donde los llamados cocoyomes, acoclames y chizos (tres apodos antiguamente utilizados para designar a grupos de encomienda de esas zonas) de pronto dieron nombre a grupos de «enemigos» tan fieros como los bien conocidos tobosos. Pero lo que terminó inquietando a los españoles fue lo acontecido más hacia el norte, a lo largo del río Grande del Norte, y en la región situada al septentrión de la Sierra Madre Occidental, en la zona de Janos, Casas Grandes y en el camino a

10 Álvarez, 2000b: 305-354. 
Sonora. En esta última región, por ejemplo, desde las décadas de 1680 y 1690 , los españoles se habían esforzado por controlar y «asentar de paz» a los indios en presidios como el de Janos, lo mismo que en algunas haciendas y en varias de las nuevas misiones creadas durante esos años: San Antonio de Casas Grandes, Santa María Nativitas de Bachíniva y Santa Ana del Torreón, entre otras. Sin embargo, lejos de pacificarlos, eso había provocado violentas rebeliones entre los tarahumaras, conchos, jocomes y janos, como las de 1684 y 1694. Pero hubo algo suplementario: a partir de esas épocas, los españoles debieron experimentar también la presencia, cada vez más numerosa y frecuente, de apaches peleando a la vera de esos grupos, especialmente, los jocomes y los janos. Lo mismo sucedió sobre la cuenca del río Grande del Norte, en la zona del Paso del Norte y en La Junta (de los ríos Grande y Conchos), en donde vemos a conchos, julimes y sumas asociados en sus ataques con bandas de apaches y de los llamados cíbolos ${ }^{11}$.

La relación de grupos como los janos y sumas con los llamados apaches es antigua en la Nueva Vizcaya. Durante el siglo XVII, numerosos apaches fueron capturados en esas mismas regiones para luego ser trasladados a las haciendas de Parral y del valle de San Bartolomé por los españoles ${ }^{12}$. Ello nos indica la existencia, entre algunas ramas de esos grupos, de vínculos culturales, los cuales siguen siendo discutidos por los especialistas ${ }^{13}$. Hasta finales del siglo XVII, los indios norteños del tipo de todos los mencionados anteriormente (incluidos los apaches) habían peleado librados a sus propias fuerzas, mientras que, a partir de ese momento, no solamente se les incorporan los apaches «de siempre» (por llamarlos de algún modo), sino que parece operarse también la progresiva llegada de guerreros montados del norte lejano, reforzando a los ya de por sí temibles indios bravos de la provincia ${ }^{14}$. La presencia de los llamados cíbolos, en referencia a que se trataba de gente proveniente de las regiones del bisonte (o vaca de Cíbola), es un testimonio a tomar en cuenta respecto de ese tipo de movimientos de poblaciones lejanas, de las cuales, la irrupción de los comanches medio siglo más tarde constituirá el evento más impactante. La segunda transformación de importancia provino del hecho de que estos guerreros del norte llegaban ya con sus propias manadas de caballos y eran, por lo mismo, mucho más autónomos en ese rubro que los grupos locales. Éstos

11 Extracto del papel que formo el Sr Don Lope de Sierra Osorio sobre las cosas tocantes al Reyno de la Nueva Vizcaya.. Sin fecha subsecuente al año de 1683, Hacket, 1923-37, 2: 218-226.

12 Cramaussel, 25 (México 1990-1991): 73-91.

13 Cramaussel, 20 (México 1992): 25-26.

14 Hackett, 1923-37, 2: 222. 
siempre dependieron fundamentalmente de los caballos de los propios españoles para operar como guerreros montados (regresaremos sobre esto más adelante), de suerte que los apaches se hicieron mucho más difíciles de atajar y perseguir que los «enemigos» de antaño, hecho que contribuyó, sin duda, a la creación de su leyenda.

En semejante contexto, nada tendría de extraño que, cualquiera que hubiera asumido el cargo de gobernador de la Nueva Vizcaya, se viera obligado a dedicar mucho tiempo a la guerra. Sin embargo, en el caso de Manuel de San Juan, lo que habría que observar es la decidida propensión que mostró desde un principio a tomar personalmente ese tipo de asuntos, más allá, incluso, de la «obligación» inmediata: no hacerlo, contribuiría muy poco a la comprensión de un personaje de este tipo. Así, por ejemplo, estando todavía en Durango, en 1715 , levantó una compañía de soldados, reforzada por un centenar de «auxiliares» tarahumaras y conchos, para perseguir a los «acoclames» y «cocoyomes» que habían asaltado haciendas y robado caballadas en Mapimí y el valle de San Bartolomé15. Igualmente encabezó una entrada contra los tarahumaras rebeldes de la región limítrofe con la provincia de Santa Bárbara. Incluso, debió preocuparse también de la presencia de otros europeos cerca de la Nueva Vizcaya, como en 1719, cuando recibió noticias del alcalde mayor de Mazatlán acerca de la presencia de tres barcos desconocidos que hacían sus reparaciones allí16. Ese mismo año daba parte también al virrey Marqués de Valero sobre grupos de franceses merodeando con sus aliados indios a setenta leguas de la villa de Santa Fe de Nuevo México, e informaba de las prevenciones tomadas tanto para la defensa de aquella provincia como para la de la Nueva Vizcaya ${ }^{17}$.

Ante todo eso, Manuel de San Juan llevó adelante una política militar y de gobierno bastante activa. Reanudó, por ejemplo, la conformación de reducciones para los indios janos, que se implantaría en la misión de San Antonio de Casas Grandes, en Bacadeguachi y en el efímero pueblo vecino de La Soledad. Formó padrones de los naturales y les condujo bastimentos, animales y aperos de labranza para su futuro mantenimiento ${ }^{18}$. Luego dictó disposiciones para

15 Campaña contra los indios que robaron caballada de Mapimí con auxilio de 95 tarahumaras, tobosos, tacuitatomes y naturales de San Francisco de Conchos y Atotonilco, Archivo Histórico de Parral (AHP), Microfilms University of Texas, El Paso (UTEP), 476-106, 1715 A.

16 García Cortés, 1992: 175

17 Mirafuentes Galván,1989: 97.

18 Testimonio de las órdenes del gobernador de la Nueva Vizcaya Manuel San Juan de Santa Cruz sobre reducción de indios janos, AHP, Microfilms UTEP, 476-108, 1716. 
que todos los indios que se hallaren fuera de sus pueblos, dispersos en sus rancherías o bien avecindados en las haciendas de españoles, se concentrasen en sus respectivos pueblos para contarlos y saber con cuántos se podía disponer para la defensa de la provincia ${ }^{19}$. En 1716 , emitió otro bando ordenando esta vez que los vecinos españoles de todas las alcaldías mayores de la provincia se mantuvieran prestos para la defensa y se realizaran alardes de armas en cada una de ellas. Igualmente, endureció y revitalizó el sistema de repartimiento de indios en la provincia, heredado de su predecesor, López de Carvajal, y expidió ordenanzas en donde vetó la presencia de bagamundos en la Nueva Vizcaya, a los que calificaba de ser los zánganos de las Repúblicas, de suerte que cualquier individuo de esa condición debería ser capturado y enviado al trabajo forzado en haciendas y minas. En las mismas obligaba también a todos los hacendados y mineros a extenderles a sus sirvientes boletas firmadas con la distinción de la naturaleza del sirviente, edad y señas que lo identifiquen, sin las cuales tendrían enteramente prohibido desplazarse de un lugar a otro ${ }^{20}$. También supervisó la creación de un grupo de cuatro nuevas reducciones de indios y misiones en la región de La Junta de los ríos Conchos y Grande del Norte. En todos esos eventos, Manuel de San Juan no se conformó con el papel de simple orquestador, sino que él mismo protagonizó y financió la formación de varias reducciones. Fue el caso de la creación, en 1716, de la misión y reducción de Santa Ana de Chinarras, situada a unos veinticinco kilómetros al noreste de la zona de Chihuahua, hecha enteramente a su costa.

Es tema común señalar que gobernantes, capitanes y simples colonos embellecían y ensalzaban sus propios méritos ocultando todo aquello que pudiera venir en desdoro de sus actuaciones. Manuel de San Juan no solamente ha sido objeto de este tipo de crítica, sino que, en su caso, ésta ha ido demasiado lejos. En efecto, cierta historiografía norteamericana reciente lo ha descrito como el «prototipo» del «funcionario corrupto» indiano, dedicado a servirse exclusivamente de su puesto para enriquecerse y hacer todo tipo de negocios a expensas de quien fuera ${ }^{21}$. Más allá de lo que pudiera decirse, en general, acerca de este auténtico lugar común historiográfico, es obvio que semejantes interpretaciones: «todo negro», sólo sirven para generar imágenes caricaturescas y deslavadas de ese tipo de personajes. A despecho de la manera como Manuel de San

19 Mandamiento del gobernador Manuel de San Juan de Santa Cruz para que los indios que se encontrasen fuera de sus pueblos regresen a los mismos, Parral, 5 de Marzo de 1715, AHP, Microfilms UTEP, 476-106, 1715 A.

20 Bando del gobernador Manuel San Juan de Santa Cruz, prohibiendo la vagancia en la Nueva Vizcaya, Archivo Histórico de Chihuahua (AHCh), Microfilms UTEP, 491-1, 1716.

21 Tracy Goode, 2000. 
Juan presentara sus propios méritos ante la Corona, lo sustancial es que este individuo se vio involucrado en eventos relevantes de la vida de su provincia y observar cómo, lejos de dejar tras de sí la imagen de un tiranuelo corrupto, como se le ha querido pintar, lo que se labró fue una posición no solamente de prestigio, sino, sobre todo, de audacia en el seno de su nueva sociedad. Eso no significa que no se hubiera involucrado en actividades económicas que le estaban vedadas como máxima autoridad de la Nueva Vizcaya. Un «negocio» difícil, por no decir imposible, de eludir para gobernadores y capitanes de presidio era el del abasto y refaccionamiento de los propios soldados bajo su mando. Los libros del ordinario de las Cajas Reales, en este caso la de Durango, muestran claramente cómo, en el norte, los soldados de los presidios, compañías volantes y demás cuerpos castrenses sostenidos por la Corona no eran pagados mes a mes, ni siquiera semestralmente, sino en una sola exhibición anual. Esto significa que para el momento en el que sus salarios eran liberados, los soldados se hallaban necesariamente endeudados, casi siempre con sus propios capitanes, o con mercaderes asociados con éstos, los cuales les adelantaban todo tipo de bienes: desde granos, carne, ropa y aperos de labranza, hasta armamento. Sabemos que Manuel de San Juan, a la par de las actividades que realizaba a su costa, se dedicó también al suministro de bienes a los soldados de diversos presidios y compañías, y que no lo hacía de manera graciosa, pues algunos de ellos llegaron a acumular deudas importantes con él22.

Otra actividad, en principio vedada para Manuel de San Juan, pero que practicó ciertamente, es la de mercader. En su juicio de residencia, varios testigos, entre ellos Juan de Basoco, quien era mercader en Parral, lo acusan de practicar el comercio, tanto por sí mismo, como por medio de interpósitas personas, no solamente en Parral, sino también en Chihuahua y sobre el camino a Sonora. Nadie negó ese hecho, pero tampoco fue considerado como una ofensa grave. Prueba de ello es el testimonio de Diego Moreno, un importante hacendado del valle de San Bartolomé, quien dijo que era verdad, pero que con ello beneficiaba a los pobres, proveyéndoles de bienes a «corto precio» ${ }^{23}$. Aunque en su juicio de residencia no se tocó ese punto, al parecer también tuvo minas durante el tiempo de su gestión como gobernador. Existe, incluso, una leyenda, propalada por Miguel de Arlegui, según la cual Manuel de San Juan, siendo gobernador, habría extraído de su mina en Santa Eulalia veinte

22 Auto de pedimentos de los soldados del presidio de Cerro Gordo a Manuel San Juan de Santa Cruz sobre sus sueldos, 1722, AHP, Microfilms UTEP, 1722C.

23 Residencia de Manuel de San Juan Santa Cruz, Gobernador de la Nueva Vizcaya, por Felipe de Otaduy y Abendaño. Testimonio de Juan de Basoco, Testimonio de Diego Moreno, AGI, Escribanía de Cámara, legajo 391B, 1720. 
arrobas de plata por semana durante tres años continuos ${ }^{24}$. Sin embargo, nada de eso hizo mella en su reputación, quizás también por haber sido discreto: en los registros de minas y repartos de azogue de los años de su gestión, Manuel de San Juan nunca aparece consignado ni como minero ni como consumidor de azogue, ni siquiera por medio de allegado alguno hasta ahora reconocible para nosotros. Así, al final, cuando en 1720 dejó el gobierno, su juicio de residencia no arrojó más consecuencia que una simple multa de quinientos pesos por cargos bastante menores: no residir en Durango, no tomarles juicio de residencia ni cobrarles medias anatas a varios alcaldes mayores y comerciar dentro de su provincia, es decir: nada que dañara verdaderamente su prestigio ${ }^{25}$.

En cambio, acontecimientos como los que rodearon la fundación de la villa de San Felipe el Real de Chihuahua, siguieron colocando a Manuel de San Juan en posición de ganar cada vez más prestigio, poder e influencia. En 1716, ordenó la realización de un recuento de los vecinos españoles que habitaban en la zona de Chihuahua, en donde aparecieron listados doscientos ochenta y nueve jefes de casa, repartidos entre los dos reales de minas principales (Santa Eulalia y San Francisco de Cuéllar) y las haciendas agrícolas de la jurisdicción. Esto significaba que, ya para ese entonces, Chihuahua había superado fácilmente en población a Cusihuiriachi y Parral, colocándose solamente por detrás de Durango y el valle de San Bartolomé en el número de habitantes españoles. Así, en 1718, siguiendo los lineamentos de la ya mencionada cédula de agosto de 1702, el propio gobernador presidió la realización de la primera traza y fundación formal de la nueva villa de San Felipe el Real de Chihuahua ${ }^{26}$. En ese momento, su vieja inclinación de mecenas, mostrada ya anteriormente en las Filipinas y en Durango, se puso nuevamente de manifiesto con la donación de cuarenta mil pesos para la construcción de la futura iglesia parroquial de la villa de San Felipe. Huelga decir que un tipo como Manuel de San Juan era consciente de lo que ese mecenazgo le aportaba: su único reclamo, a cambio del donativo, fue ser considerado como fundador de la obra, nada menos ${ }^{27}$. También sabía que, con eso, desplazaba al que hasta entonces había fungido como el «hombre fuerte» de la región de Chihuahua: el coronel Juan Antonio de Trasviña y Retes. Éste era un poderoso minero, proveniente de Cusihuiriachi, dueño de una hacienda de minas llamada La Regla, inmediata al sitio de la

24 Arlegui, 1851: 91-92.

25 Residencia de Manuel de San Juan Santa Cruz, Gobernador de la Nueva Vizcaya, por Felipe de Otaduy y Abendaño. Autos de sentencia, AGI, Escribanía de Cámara, legajo 391B, 1720.

26 Cramaussel-Álvarez, 1992: 45-69.

27 Bargellini, 1984: 46. 
nueva villa, y quien había financiado con dieciocho mil pesos la construcción del templo primitivo de San Francisco de Cuellar, real de minas precursor de la villa de Chihuahua. Ambos, Trasviña y Manuel de San Juan, por igual, se proclamarían más tarde como fundadores de Chihuahua y benefactores de la iglesia local y, sin embargo, fue claramente el segundo el que más se benefició de ello ${ }^{28}$.

No obstante, dentro de todo este panorama favorable, un evento familiar, del cual no fue realmente responsable, terminaría por nublar a la larga su porvenir y sobre todo el de su familia. Éste ocurrió en 1709, esto es, cinco años antes de su nombramiento como gobernador de la Nueva Vizcaya, cuando se descubrió la desaparición de un embarque de plata y otros bienes por valor de 122.775 pesos que iba de Acapulco a Veracruz. Las averiguaciones comenzaron de inmediato y muy pronto llegaron hasta Francisco de San Juan, el cual fue considerado responsable de lo perdido en tanto que tesorero de la Caja Real de Veracruz. Sin embargo, no fue el único involucrado. También se hicieron averiguaciones en contra del contador de la caja de Veracruz, Pedro de Carrasco y Aguilar, y de Juan de Veitia Linaje, juez de arribadas de Acapulco ${ }^{29}$. La pesquisa, sin embargo, no arrojó resultado alguno durante largos años, y es importante recalcar que, aunque se hallaba en curso en el momento de la erección de Manuel de San Juan como gobernador de la Nueva Vizcaya, en nada estorbó su nombramiento. De hecho, Manuel bien pudo haber sido considerado como solidario en la reparación del daño y, si bien en ese momento nada de eso ocurrió, años más tarde, la desaparición física de los directamente involucrados en el incidente haría que la Real Hacienda volviera sus ojos hacia él, como veremos después.

\section{UN HACENDADO LATIFUNDISTA Y JEFE DE GUERRA FRONTERIZO}

El fin de su gestión como gobernador no significó el término de la actividad de Manuel de San Juan como mecenas. En 1721, instituyó un fondo de treinta mil pesos para la construcción del edificio del colegio de los jesuitas en la villa de San Felipe, con indicación de que, una vez finalizada la obra, los réditos del fondo se utilizaran para la educación de los hijos de los españoles e indios. Con esta donación, el sitio de Manuel de San Juan en la sociedad local

28 Porras Muñoz,1966: 636.

29 Autos seguidos sobre el descubrimiento de 122,775 p que en 1709 se remitieron por los oficiales reales del puerto de San Diego de Acapulco a los de la ciudad de Veracruz, Archivo General de la Nación, México (AGN), Tierras, legajo 375, exp. 3. 
se hizo todavía más firme y definitivo. Su casa en San Felipe, situada frente a la iglesia de la Tercera Orden franciscana, fue una de las primeras dentro de la traza, cuya creación él mismo había presidido y, por el otro lado, su mina en Santa Eulalia, llamada Dulce Nombre de Jesús, parece haber sido una de las más productivas de ese real si se le da fe al ya citado testimonio de Arlegui. El comentario aquí podría ser poco más o menos el mismo que cuando se relataron sus primeros años en la Nueva España. Era ya un hombre prestigioso y digno de fe, gran minero, dueño de tiendas en varias partes de la provincia y beneficiario, además, de una red de posibles socios comerciales que hubiera podido extenderse, fácilmente, hasta la Nueva España, el Perú y las Filipinas. Sin embargo, en vez de consagrarse a fomentar sus caudales «minero y comerciante», prefirió adquirir tierras y seguir ligado al camino de las armas.

En 1724, Blas Cano de los Ríos, quien fuera propietario de una de las más importantes haciendas de la jurisdicción de Chihuahua, San José del Sacramento, falleció dejando siete hijos menores, los cuales no habitaban ya en Chihuahua, sino en la ciudad de México. En esa circunstancia, Miguel Cano de los Ríos, tío y tutor de los menores, decide poner la hacienda en almoneda, la cual es ganada por Juan de Subia Pacheco, un rico y poderoso hacendado del valle de San Bartolomé. Éste había sido arrendatario de esa hacienda por casi dos décadas y poseía, además, un derecho de tanto sobre ella, es decir, de prioridad en caso de venta, por lo que el juez de comisión no tuvo problemas en avalar esa operación. Sin embargo y a pesar de que se trataba, al menos en principio, de un caso cerrado, Manuel de San Juan irrumpe intempestivamente en la negociación, ofreciendo directamente a los herederos doce mil pesos por la hacienda, esto es, casi el doble de los seis mil seiscientos aportados por Juan de Subia. Los herederos aceptan la oferta de Manuel de San Juan, quien rápidamente toma posesión de Sacramento ante una muy tibia oposición de Juan de Subia, quien solamente dirigió un escrito a la audiencia sobre la violación de un derecho adquirido desde hacía casi dos décadas, pero luego desalojó rápidamente el predio. Tan sólo un par de años después, el litigio terminó con el desistimiento de Subia Pacheco, quien sólo pidió ser resarcido de lo gastado y que la hacienda quedara gravada con una capellanía de 4.000 pesos al 5\% anual, cuyos réditos serían disfrutados por un hijo suyo del mismo nombre: el licenciado Juan de Subia ${ }^{30}$.

30 Concurso de bienes de Miguel Cano de los Ríos, Manuel San Juan de Santa Cruz, comprador de la hda Sacramento con capellanía a favor del lic Juan de Subia hijo de Juan de Subia Pacheco, 1724, Centro de Estudios de Historia de México CARSO [CARSO], Archivo Pablo Martínez del Río, Títulos de Encinillas. 
El lapso inusualmente corto en el que se resolvió este diferendo y el hecho de que dos poderosos hacendados del Valle de San Bartolomé, como lo eran Juan de Subia Pacheco, dueño de la hacienda llamada por entonces de Ana de Aldaz, y el propio Miguel Cano de los Ríos, que lo era de la de San Gerónimo, hubieran cedido tan fácilmente frente a las pretensiones de Manuel de San Juan, es una muestra clara de lo que este hombre pesaba en la sociedad local. Manuel, por su parte, lejos de conformarse con lo ya adquirido, siguió en busca de tierras. Una nueva oportunidad se le presentó cuatro años después, en 1730, con el fallecimiento de Benito Pérez de Rivera, quien era propietario de la hacienda de Encinillas, con su anexo, la hacienda de Los Sauces, ambas vecinas inmediatas de la de Sacramento por la banda del norte. El proceso de adquisición de Encinillas y Los Sauces fue muy semejante al anterior. Pérez de Rivera no tenía aparentemente herederos, de manera que, en cuanto Elvira Hernández de Córdoba, su principal acreedora en Chihuahua, hizo la demanda, las haciendas fueron puestas a remate. Como en el caso de Sacramento, nadie respondió al llamado, excepto Manuel de San Juan, quien hizo una primera postura por trece mil pesos, la cual él mismo incrementó de inmediato hasta los dieciséis mil quinientos pesos. No habiendo más postores, el juez comisario, Domingo Vélez de Rivero, dio por buena la venta. Sin embargo, esta vez la oposición vino un poco después, por boca de un tal Bernardo de Miranda Villazán, quien era apoderado de otros acreedores de Pérez de Rivera y estaba provisto de un mandato de la audiencia ordenando la realización de un nuevo remate, procedimiento que se verificó al año siguiente. En esta ocasión, Manuel ofreció veinte mil pesos en reales, o su equivalente en plata, pagaderos en un año, con $5 \%$ de réditos. Como en las ocasiones anteriores, nadie más osó mejorar la postura y la adquisición quedó sellada definitivamente ${ }^{31}$.

Una vez adquiridas estas dos haciendas fundadoras de Chihuahua, el siguiente paso fue unirlas en un solo dominio territorial. Encinillas databa de 1676, cuando Domingo de Apresa Falcón, tío de Benito Pérez de Rivera, se trasladó al por entonces «nuevo descubrimiento de Chihuahua» y plantó el que sería el primer asentamiento permanente en Chihuahua: la hacienda de Santo Domingo de Tabalaopa, cedida en 1718 por una hija suya, María de Apresa Falcón, a la Compañía de Jesús. Mientras tanto, su sobrino, Benito Pérez de Rivera, obtenía un poco más al norte una merced de cuarenta sitios de ganado mayor, a los cuales se anexaron luego los siete sitios de la hacienda del Sauz, que fue lo que compró Manuel de San Juan. Por su parte, Sacramento databa

31 Concurso de bienes de Benito Pérez de Rivera, 1730, CARSO, Archivo Pablo Martínez del Río, Títulos de Encinillas. 
de 1696, cuando su fundador, Blas Cano de los Ríos, adquirió una merced de cien sitios de ganado mayor más allá del pueblo de indios de Nombre de Dios, sobre la rivera occidental del río que da nombre a la hacienda. Sin embargo, cuando hacia 1710, Juan de Subia Pacheco arrendó el predio, el trato no versó sobre todo lo mercedado originalmente a Cano de los Ríos, sino sólo sobre la parte en donde se encontraba la casa principal de la hacienda, con sus tierras de riego y las estancias de ganado más próximas a las mismas: una extensión equivalente a cinco sitios y medio de ganado mayor. Juan de Subia Pacheco acondicionó y cultivó esa parte de la hacienda, la cual fue nombrada propiamente Hacienda de Labor de San Joseph del Sacramento. Sin embargo, en el momento de negociar los veinte mil pesos en que se cifró la operación final, Manuel tuvo buen cuidado de solicitar a los herederos de Cano de los Ríos la cesión de los derechos amparados en la merced original del Sacramento por cien sitios de ganado mayor ${ }^{32}$. Una vez con las dos haciendas y la referida merced en sus manos, Manuel de San Juan conservó siempre la hacienda de labor del Sacramento como una unidad aparte, con las dimensiones que había adquirido en tiempos de Subia, mientras que el resto de los sitios mercedados a Cano de los Ríos, y adquiridos entretanto por él, los incorporó en sus posteriores composiciones de tierras a la hacienda de Encinillas, la cual quedó convertida en la mayor de sus propiedades.

Lo que estaba haciendo Manuel de San Juan en aquel momento no era ningún capricho, sino algo que iba perfectamente de acuerdo con la lógica de la ocupación española en los territorios del norte. Para entender esto, recordemos que, desde muy temprano, en la legislación indiana se dispuso que las tierras de pasto ocupadas por ganado, es decir, las «estancias de ganado» en el sentido literal del término, pudieran ser adquiridas y detentadas en propiedad por quien las denunciara, pero sólo, siempre y cuando fuera capaz de «poblarlas», es decir, de colocar vaqueros permanentes en ellas, encargados de mantener los animales reunidos, vigilados y marcados. Se trataba entonces de una forma de acceso a la propiedad territorial, exclusiva de personajes capaces de tener a su servicio grupos enteros de gente a caballo: cuanto más numerosos fueran éstos, mayores las extensiones dominadas por esa vía ${ }^{33}$. De hecho, como lo hemos descrito ya en trabajos anteriores, una gran parte de las haciendas creadas en las tierras nuevas del norte de la Nueva Vizcaya durante el medio siglo an-

32 Testimonios de autos sobre la entrega de los bienes de la tercera clase que quedaron por muerte de Don Manuel de San Juan de Santa Cruz a su sobrino Don Manuel Antonio de San Juan de Santa Cruz Jaques, San Felipe el Real, 28 de octubre de 1752, AGN, Tierras, legajo 744 , exp. 2.

33 Álvarez, 2010. 
terior surgieron de «sitios de estancias», es decir, «tierras de ganados» no ocupadas ni tituladas anteriormente y que fueron progresivamente «pobladas» por los hacendados y señores de ganados locales por intermedio de sus vaqueros, sirvientes y allegados: Manuel de San Juan planeaba hacer lo mismo.

En ese tiempo, el viejo casco de Encinillas no contaba más que con dos casas viejas de dos habitaciones, un corral con toril, con un centenar de vacas, toros, vaquillas y becerros, otro más con ciento ocho caballos y potros mansos, una manada de yeguas para cría de mulas y algunas herramientas viejas. Los jueces valuadores que realizaron el inventario de Encinillas con motivo de esa venta, apuntaron que, fuera de lo anterior, la única riqueza de la hacienda eran algunas cabezas de ganado mayor dispersas por los terrenos de la hacienda, sin herrar y revueltas con ganado ajeno. Sin embargo, a falta de vaqueros locales, los jueces debieron de buscar algunos de fuera que las separaran y las contaran: resultó entonces que solamente quedaban 1390 cabezas en el predio ${ }^{34}$. El testimonio de los jueces valuadores era muy claro: sin gente y, por lo tanto, sin vaqueros que reunieran el ganado disperso por las «estancias» de que estaba compuesta, una hacienda de ese tipo no valía realmente gran cosa. Cabría preguntarse entonces por qué Manuel de San Juan se había empeñado en hacerse de Encinillas. La respuesta puede encontrarse en las características de este dominio territorial. Uno de sus rasgos más singulares era la gran laguna endorreica, llamada originalmente de San Juan, que se hallaba en el centro del valle que le daba nombre a la hacienda y que medía unos cincuenta kilómetros de largo por veinte de ancho. Inútil para fines propiamente agrícolas, esta pieza de agua relativamente salobre era, en cambio, una fuente casi permanente de pastos de diversos tipos, algunos verdes y comestibles, útiles no solamente para los animales ya mencionados, sino para otro mucho más importante todavía: el caballo. A nadie podría extrañar el hecho de que las grandes haciendas norteñas se ubicaran preferentemente a la vera de corrientes y cuerpos de agua, como puede apreciarse en las cartas 1 y 2 . Sin embargo, no hay que imaginar que esto se debiera solamente a la necesidad de agua para riego, como se ha repetido últimamente hasta la saciedad: ése era solamente un aspecto de la cuestión. El otro, en ocasiones más importante aún en este contexto geográfico, estaba constituido por aquellos pastos de ciénaga, de río o de laguna, los cuales en ese norte árido se revelaron como especialmente propicios para la cría de diversos animales, entre ellos, el ganado caballar.

A diferencia de las grandes llanuras norteamericanas, en donde el caballo asilvestrado prosperó espontáneamente, dando pie al nacimiento del indio

34 Domingo Velez de Rivero juez valuador. Avalúo de Encinillas. Concurso de bienes de Benito Pérez de Rivera, 1730, CARSO, Archivo Pablo Martínez del Río, Títulos de Encinillas. 
montado de aquellas regiones, en el Septentrión Novohispano, el caballo salvaje, si bien existió, no alcanzó grandes números. Este fenómeno, nunca estudiado hasta ahora, pero del cual podemos suponer que estuvo ligado con factores esencialmente climáticos, determinó que los indios bravos de esas regiones dependieran casi siempre de animales criados en las estancias de los españoles para poder servirse de ellos en sus correrías: de allí su permanente propensión a robárselos cada vez que podían. Pero lo más importante es que los propios españoles dependían también de los criadores de caballos, esto es, de los grandes hacendados, para poder andar montados. En el norte árido novohispano, la cría de caballos quedó reservada con frecuencia para haciendas de gran tamaño, capaces de contener cuerpos de agua permanentes, generadores de pastos diversos, y era no menos frecuente también que ese tipo de haciendas terminara quedando en manos de jefes de armas, como Valerio Cortés del Rey, Francisco Montaño de la Cueva, Lope del Hierro Cereceda y Domingo de Apresa, por mencionar solamente algunos. Todos ellos fueron connotados capitanes de guerra y, a la vez, hacendados latifundistas y criadores de caballos. Lo mismo puede decirse de los más famosos y durables capitanes de los presidios neovizcaínos, como Juan de Barraza, Juan Fernández de Retana y Juan Bautista de Escorza, entre otros, todos ellos, igualmente, hacendados y criadores de caballos ${ }^{35}$.

No cabe duda que entre los planes de Manuel de San Juan se encontraba el transformar a Encinillas en ese tipo de hacienda, y de hecho lo logró en un tiempo sumamente corto. Bajo su sombra, la hacienda creció en población quizás como ningún otro asentamiento de españoles en la provincia durante ese tiempo. De haber estado prácticamente vacía, para mediados de la década de 1740 , la hacienda contaba ya con más de cincuenta vaqueros y unos cuarenta pastores de ovejas, además de un buen centenar de labradores, peones de campo y artesanos. Muchos de ellos eran jefes de familia, de manera que la población de la hacienda puede estimarse fácilmente en más de dos mil personas para ese tiempo, lo cual hacía de aquél uno de los dominios territoriales más importantes del norte novohispano ${ }^{36}$. Conforme los vaqueros y peones de campo se fueron multiplicando, la hacienda fue creciendo también en territorio, de manera que, para 1750, esto es, poco antes de la muerte de Manuel de San Juan, Encinillas contaba ya con una extensión titulada equivalente a $242 \frac{1}{2}$ sitios de ganado mayor (425.735,4 ha). Pero eso no fue todo, conforme aumentó el número de gente a su servicio y órdenes, Manuel de San Juan fue adquirien-

35 Álvarez, 1999: 48-71.

36 Domingo Vélez de Rivero juez valuador. Avalúo de Encinillas. Concurso de bienes de Benito Pérez de Rivera, 1730, CARSO, Archivo Pablo Martínez del Río, Títulos de Encinillas. 
do y poblando toda una serie de anexos y extensiones de Encinillas, cuyo número y superficie pueden resumirse de la manera siguiente: Ojo Caliente (4 sitios), Cañada de la Primavera y Noria (10 sitios), Puesto de Huerachi (12 sitios), Potrero de San Joseph y rancho de Majalca (35 sitios), Puesto La Primavera (42 sitios), Hacienda de Santa Bárbara, alias San Pedro (22,5 sitios), Sierra de San Andrés y Carbonera de Aguilar (3 sitios) ${ }^{37}$. En total: 376,5 sitios de ganado mayor (incluyendo la hacienda de Sacramento), equivalentes a 660.983,4 hectáreas, todo ello sin contar las extensas demasías, esto es, tierras sin medir y desde luego sin titular, que eran controladas por gente de la hacienda (ver carta n. ${ }^{\circ}$ ).

Se calculaba que para ese tiempo podía haber en tierras de la hacienda más de cien mil cabezas de ganado mayor, mucho de él «orejano» (es decir, cimarrón y sin herrar), además de un número cuando menos dos veces más grande de ovejunos y ciertamente bastantes caprinos. Junto con todo eso, al menos un par de millares de caballos pastaban también en los sitios de crianza que se habían abierto en diferentes puntos de la hacienda ${ }^{38}$. Pero, en realidad, Encinillas había dejado de ser una hacienda solamente ganadera. Como mencionábamos antes, había en ella un centenar de peones de campo, de los cuales muchos eran exclusivamente labradores y ello le había permitido convertirse en una importante productora de granos, en especial de trigo. La hacienda contaba, además, con artesanos especializados que producían diversos bienes para la población local: dos apicultores, un jabonero, un albañil, un sombrerero, un baquetero y un herrero, cada uno de ellos con sus respectivos ayudantes, además de catorce trabajadores de minas, entre tenateros y barreteros. Desde luego también había trasquila, encarnadero, es decir, carnicería, y molino, además de que tenían cinco trenes de mulas para los intercambios con el exterior. Sin embargo, uno de los rasgos más sobresalientes de la hacienda era su obraje, el mayor de la Nueva Vizcaya, cuya mano de obra oscilaba entre una veintena y medio centenar de trabajadores, dependiendo de las llegadas de cautivos de guerra, pues era, efectivamente, un establecimiento operado por gente condenada a trabajos forzados, entre los que había apaches, tiguas y tarahumaras. Además de todo lo mencionado, en los extensos «anexos» con los que contaba la hacienda, como los de La Primavera y Majalca, había madera para

37 Fernando Velarde, valuador de bienes que quedaron por fin y muerte de Manuel de San Juan de Santa Cruz, Avalúo de las haciendas de Sacramento y Encinillas, AGN, Tierras, legajo 744, exp. 1, 1752.

38 Despacho para que se embarguen los bienes de Manuel San Juan de Santa Cruz, sus haciendas en Nueva Vizcaya, Cuautitlán, y la ciudad de México, AGN Tierras, legajo 375, exp. 3, 1750 . 
Carta no. 2

\section{Evolución del latifundio}

Encinillas,1675-1750

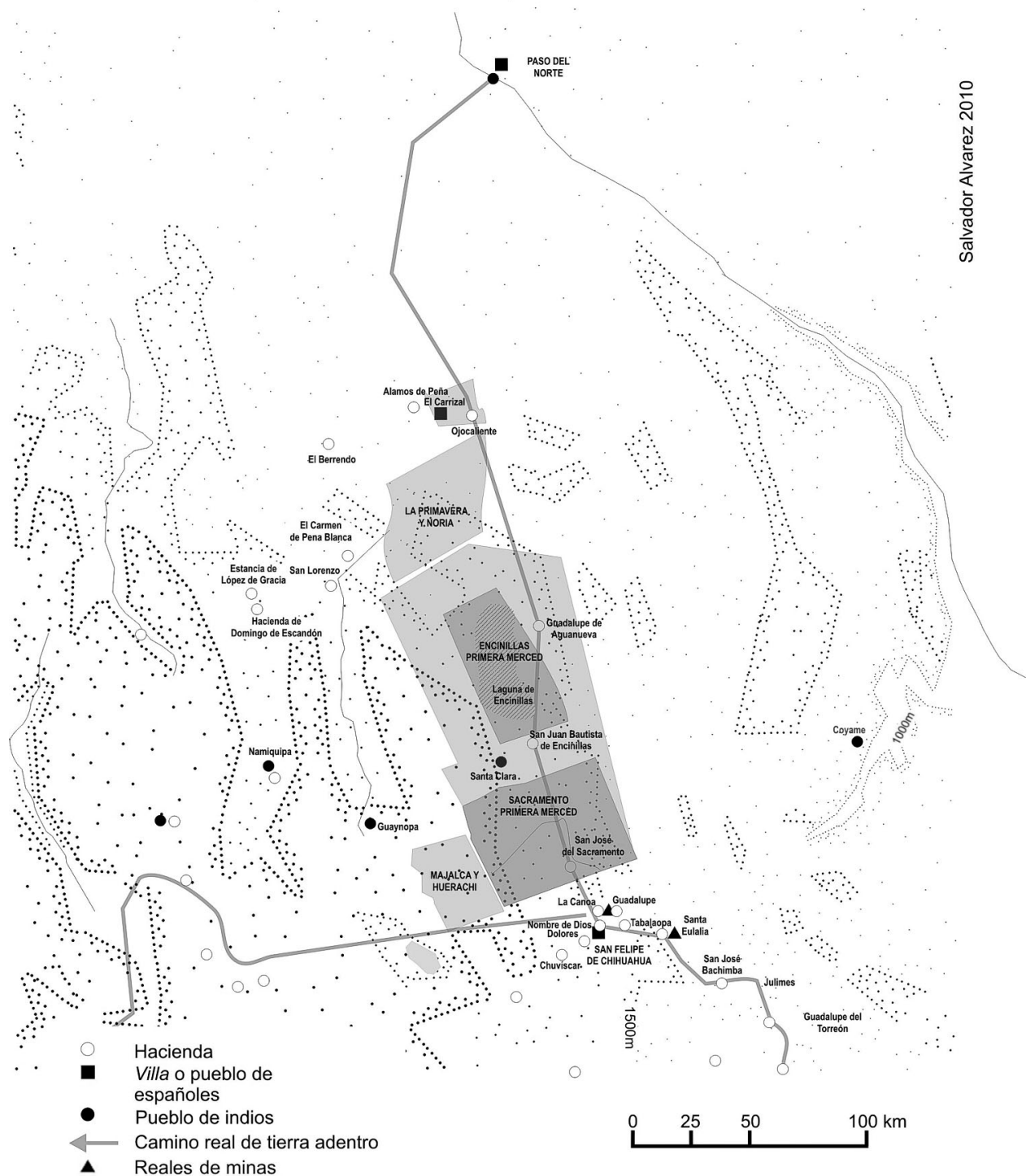


leña y carbón en abundancia. Todo ello hacía de Encinillas un dominio prácticamente autosuficiente en muchos rubros, aunque, desde luego, «ligado» con el exterior por la vía de los intercambios, como todas las haciendas autosuficientes de su tipo. Durante varios años, Manuel de San Juan fue el titular del abasto de carne de Chihuahua, lo cual le significaba envíos que se pueden estimar en, por lo menos, 2.300 reses anuales (probablemente bastante más, el cálculo es inicial) y se sabe que la hacienda vendía también frazadas de dos tipos producidas en el obraje, tanto en Chihuahua como en Paso del Norte, a un ritmo que podría calcularse en alrededor de seis mil piezas anuales. Igualmente se expendían objetos de cuero de diferentes tipos, cebo para velas, sal de sus ciénagas, leña y carbón, entre otros varios productos ${ }^{39}$.

Sin embargo, nada resultaría más empobrecedor que hablar de Encinillas como de una "empresa comercial», "capitalista», pues era mucho más que eso. Sería, por ejemplo, imposible entender el funcionamiento de esta hacienda latifundista sin considerar el carácter marcadamente militar que Manuel de San Juan le imprimió a su organización interna. Desde épocas muy tempranas, las grandes haciendas latifundistas de la Nueva Vizcaya fungieron siempre como las principales protectoras de los viandantes que atravesaban por sus tierras. Esa es la razón por la cual en regiones como Durango, o el Valle de San Bartolomé, de alta concentración de haciendas, nunca hubo necesidad de instalar presidios fijos, dado que eran los hacendados con sus huestes armadas los que cumplían esa función y lo mismo hizo Manuel de San Juan con Encinillas en la región situada al norte de Chihuahua ${ }^{40}$. Como puede verse en la carta n. ${ }^{\circ}$ 2, una gran parte del trayecto del Camino Real de Tierra Adentro entre Chihuahua y Paso del Norte atravesaba justamente por terrenos ocupados por la hacienda y sus anexos. Allí eran los vaqueros armados de Manuel de San Juan los que se ocupaban de la protección de los viandantes y, en caso necesario, también de la persecución de los indios. Es evidente que esa tropa no estuvo conformada solamente por gente de a caballo bien adiestrada en el arte de lidiar con el ganado cimarrón disperso en aquellas secas bastedades, sino que eran, además, individuos experimentados en el uso de las armas, capaces de enfrentar y hasta perseguir a indios bravos de todo tipo, incluyendo a los temibles apaches. Todas estas eran cualidades que no se conseguían simplemente ofreciendo un salario en «metálico» al primero que pasara por allí. Además de las habilidades mencionadas, fue necesario también desarrollar entre esa gente

39 Fernando Velarde, valuador de bienes que quedaron por fin y muerte de Manuel de San Juan de Santa Cruz. Avalúo de las haciendas de Sacramento y Encinillas, AGN,Tierras, legajo 744, exp. 1, 1752.

40 Álvarez, 1999. 
lealtades y alicientes que iban más allá de lo económico, para asegurar su permanencia en tan problemático «empleo». Cuando menos en un principio, esa tropa bien pudo estar formada por gente que había acompañado a Manuel de San Juan en alguna de sus correrías como gobernador y capitán general y que había llegado hasta Encinillas atraída por el ascendiente que este hombre siguió ejerciendo como jefe de armas. Sin embargo, conforme transcurrió el tiempo, fue necesario que estos patrones de vida castrense se convirtieran en parte de la cultura y modo de vida internos de la hacienda.

Las cualidades de Encinillas como «atalaya» y «bastión» contra los indios fueron muy rápidamente reconocidas, incluso, por las autoridades virreinales. Así, por ejemplo, en 1738, el virrey-obispo Juan Antonio de Vizarrón nombró a Manuel de San Juan teniente de Gobernador y Capitán General de la Nueva Vizcaya, con jurisdicción sobre toda la parte norte de la provincia en sus linderos con el Nuevo México, con amplios poderes en lo militar. Con este nombramiento, el virrey simplemente formalizaba el hecho de que era Manuel el que sostenía, prácticamente a su costa, gran parte de la actividad militar en esa parte de la provincia. Durante los años 1740-1750, casi la totalidad del abasto del presidio de Paso del Norte corrió por cuenta de Encinillas. Ese último año fueron enviados hasta esa guarnición, por ejemplo, 2.413 reses para el mantenimiento de los soldados, e igualmente la hacienda fungió como su principal proveedora de caballos ${ }^{41}$. Este es un punto importante. Recordemos que la práctica consagrada por el tiempo y escriturada más tarde en los reglamentos de los presidios norteños, indicaba que cada soldado debía mantener en permanencia, cuando menos, diez caballos para recambio. En el caso del presidio de El Paso, cuya tropa estaba compuesta en ese tiempo por cincuenta solda$\operatorname{dos}^{42}$, eran necesarios, al menos, quinientos caballos listos para el combate. Si a ello se añade el número de monturas que la propia hacienda de Encinillas necesitaba para el uso de sus vaqueros-soldados, para sus actividades corrientes y para la venta al exterior, tendremos que concluir que la producción de este tipo de animales no era nada pequeña. Todo ello puede dar una idea de la importancia que tenían estas haciendas criadoras de equinos $\mathrm{y}$, sobre todo, del poder que podían llegar a ejercer sus propietarios en esta clase de contextos.

41 Razón de las reses que se sacaron de los rodeos de las haciendas de Encinillas enviadas al Presidio de Paso del Norte, AGN, Tierras, legajo 744, exp. 1, 1752.

42 Navarro García, 1964: 61. 


\section{EPÍLOGO: UN GRAN DOMINIO TERRITORIAL NORTEÑO}

La conformación del latifundio de Encinillas, a la cual Manuel de San Juan le dedicó, casi por entero, los últimos años de su vida, fue, sin duda, el objetivo y al mismo tiempo el mayor de los logros de su carrera como hombre de armas en Indias. El desarrollo inicial de este latifundio nos puede ilustrar acerca del funcionamiento interno real de otras grandes heredades norteñas de talla semejante, como, por ejemplo, el marquesado de Aguayo y el condado de San Pedro del Álamo. Una rápida mirada a la vida de Manuel de San Juan y su relación con Encinillas nos muestra que la conformación de un dominio territorial de este tamaño y características no puede explicarse solamente como producto de la «necesidad de prestigio» o de una simple «inclinación» hacia un «modo de vida aristocrático» por parte de sus propietarios. El condado de San Pedro del Álamo, por ejemplo, fue creado como tal por un comerciante y no por un hombre proveniente del mundo de las armas ni de la tierra. Nos referimos a Pedro Sánchez de Tagle, sobrino de Luis Sánchez de Tagle, dueño de uno de los principales bancos de plata de la Nueva España. Sin embargo, no hay que olvidar que el mencionado título nobiliario portaba el nombre de una hacienda mucho más antigua, la cual fue comprada por este individuo ya constituida y en pleno funcionamiento ${ }^{43}$, es decir, de forma semejante a la empleada por Manuel de San Juan para adquirir Sacramento y Encinillas. Sin embargo, es evidente que, ni en uno ni en otro caso, estas adquisiciones explican el origen, el funcionamiento, ni mucho menos el destino que este tipo de dominios territoriales tuvo en la vida social y económica de ese tiempo y regiones.

Es muy probable, por ejemplo, que en un determinado momento, Manuel de San Juan hubiese intentado la conformación de un mayorazgo e incluso la obtención de un título nobiliario basado en Encinillas. Sin embargo, existieron circunstancias externas que le impidieron hacerlo. Después de la muerte de su hermano Francisco en 1724, el proceso judicial acerca del ocultamiento del embarque por 122.775 pesos continuó. Ante la desaparición física del que fue perfilándose como el principal implicado en el «fraude» en 1748, la Real Hacienda volvió los ojos finalmente hacia Manuel de San Juan, declarándolo solidario de la deuda y poniendo entonces sus bienes bajo «secuestro». Poco después, en 1749, Manuel de San Juan fallece en Encinillas a la avanzada edad de setenta años, de suerte que el proceso recae sobre su sobrino Manuel de San Juan de Santa Cruz Jaques (hijo de su hermano Francisco), quien había quedado como albacea testamentario de su nieta menor, Romana Mendivil San Juan

43 Vargas-Lobsinger, 1993: 38-44. 
de San Juan de Santa Cruz, y podatario universal para todos sus negocios y asuntos. Éste logra que las haciendas de Nueva Vizcaya no sean ya tocadas por la Real Hacienda en razón, se dice allí, de su importancia como bastiones de defensa contra los «indios bárbaros», de modo que el fisco real debió conformarse con incautar y vender judicialmente los bienes que Manuel de San Juan poseía en la Nueva España. Éstos eran sus haciendas de Cuautitlán, San Pedro Cuamantla y San Nicolás de Lanzarote, sus cuatro casas en la ciudad de México, además de su hacienda de minas Dulce Nombre de Jesús, esta sí, en Santa Eulalia de Chihuahua ${ }^{44}$. Así se hizo y con ello la vieja deuda con la Real Hacienda se consideró saldada.

Entretanto, Encinillas llevó en adelante una vida «propia», llamémosle así, larga y complicada. Durante todo el siglo XVIII, la hacienda continuó operando poco más o menos de la misma forma que en tiempos de Manuel de San Juan, conservando, incluso, sus funciones militares y defensivas. Así, por ejemplo, en 1757, el presidio de El Paso fue trasladado al poblado del Carrizal, fundado por Manuel de San Juan sobre tierras pertenecientes a uno de los anexos de Encinillas: el sitio del Ojo Caliente. Su sobrino, Manuel Antonio, fue nombrado capitán vitalicio de ese nuevo presidio, cuyo sostenimiento corrió también a cargo de la hacienda, administrada por él en ese tiempo hasta su muerte en $1758^{45}$. La hacienda queda entonces totalmente en manos de Romana Mendivil de San Juan de San Juan de Santa Cruz, quien se casa poco después con Miguel González de Cosío, otro rico hacendado de la región de Chihuahua. Mientras Encinillas permanece en manos de este último como su administrador, la vida en ella sigue su curso normal como hacienda y bastión defensivo. Todavía en 1773, por ejemplo, Hugo de O'Connor, consultado sobre la conveniencia de abrir un presidio en esa zona, simplemente optó por contar a la hacienda de Encinillas entre los «bastiones» de la Nueva Vizcaya ${ }^{46}$. Sin embargo, con la independencia, la vida de la hacienda se renueva radicalmente. Después de una serie de sucesiones femeninas que la hacen cambiar de manos con cada tránsito generacional, en 1843, Encinillas es arrendada por Ángel Trías padre, quien la saquea sistemáticamente y prácticamente la destruye como complejo territorial y productivo ${ }^{47}$. Muy decaída, en 1854, su en-

44 Testimonios de escrituras de venta de la Hacienda de Encinillas por el notario Néstor Montes, Chihuahua, 6 de Agosto de 1856, CARSO, Archivo Pablo Martínez del Río, Títulos de Encinillas.

45 Navarro García, 1964: 354.

46 Navarro García, 1964: 354.

47 Testimonio de la escritura de venta de la Hacienda de Encinillas y de la cesión de derechos de las mejoras de la misma otorgada por la 1. ${ }^{a}$ por Don Antonio González de Portugal y 
tonces propietaria, Concepción Cosío, la vende a Pablo Martínez del Río, de cuyos descendientes la adquiere, a su vez, Luis Terrazas en 1889 para convertirla en el centro de un inmenso latifundio de más de dos millones de hectáreas. Pero esa es ya otra historia.

\section{BIBLIOGRAFÍA}

Álvarez, Salvador, «La hacienda-presidio en el Camino Real de Tierra Adentro en el siglo XVII», Transición, 22 (Durango, agosto 1999): 48-71.

Álvarez, Salvador, «Agricultores de paz y cazadores-recolectores de guerra: los tobosos de la cuenca del río Conchos en la Nueva Vizcaya», Marie-Areti Hers, José Luis Mirafuentes, María de los Dolores Soto y Miguel Vallebueno (eds.), Nómadas y sedentarios en el norte de México. Homenaje a Beatriz Braniff, México, Universidad Nacional Autónoma de México, 2000a: 305-354.

Álvarez, Salvador, «Colonización agrícola y colonización minera: la región de Chihuahua durante la primera mitad del siglo XVIII», Salvador Bernabéu Albert (ed.), El septentrión novohispano: ecohistoria, sociedades e imágenes de frontera, Madrid, Consejo Superior de Investigaciones Científicas, 2000b: 73-108.

Álvarez, Salvador, «Latifundio y poblamiento en el norte de la Nueva Vizcaya», Chantal Cramaussel (coord.), Demografia y poblamiento del territorio (siglos XVII-XIX), Zamora, El Colegio de Michoacán, 2010, pp. 147-171.

Álvarez, Salvador, «El latifundio y la Historia Económica del Norte novohispano. Por una relectura de la obra de François Chevalier», Camille Foullard (ed.), Las escuelas historiográficas de Francia y México: circulación, recepción y debate. Homenaje a François Chevalier, México, CEMCA, en prensa.

Arlegui, José de, Crónica de la provincia de Nuestro Seráfico Padre San Francisco de Zacatecas, 1737, México, Imprenta Cumplido, 1851.

Bargellini, Clara, La Catedral de Chihuahua, México, Universidad Nacional Autónoma de México, Instituto de Investigaciones Estéticas, 1984.

Blair, Emma Helen y Robertson James, Alexander, The Philippine Islands, 1493-1803: Explorations by Early Navigators, Descriptions of the Islands and their Peoples, their History and Records of the Catholic Missions..., Cleveland, Ohio, A.H. Clark Co., 1909, vol. 47.

Cramaussel, Chantal y Álvarez, Salvador, «El plano de 1722 de la villa de San Felipe el Real de Chihuahua», Arte y coerción, México, Universidad Nacional Autónoma de México, Instituto de Investigaciones Estéticas, 1992: 45-69.

la 2. ${ }^{a}$ por el Sr. Gral. Don Ángel Trías ambas a favor del Sr. Don Pablo Martínez del Río, CARSO, Archivo Pablo Martínez del Río, Títulos de Encinillas.

Navarro García, 1964: 354. 
Cramaussel, Chantal, «Encomiendas, repartimientos y conquista en Nueva Vizcaya», Historias, 25 (México, 1990-1991): 73-91.

Cramaussel, Chantal, «Los apaches en la época colonial», Cuadernos del Norte, 20 (Chihuahua, 1992): 25-26.

Labayru y Goicoechea, Estanislao Jaime, Historia general del señorío de Bizcaya, Bilbao, La Gran Enciclopedia Vasca, 1967, vol. 6.

García Cortés, Adrián, La fundación de Mazatlán y otros documentos, México, Siglo XXI Editores, 1992.

González Franco, Glorinela, Artistas y artesanos a través de fuentes documentales, México, Instituto Nacional de Antropología e Historia, 1994-1995, vol. 1.

Hackett, Charles W., Historical Documents Relating to New Mexico, Nueva Vizcaya and approaches there to 1773, Washington, Carnegie Institution, 1923-37, 3 vols.

Martínez de Cosío, Leopoldo, Los caballeros de las Órdenes Militares en México. Catálogo biográfico y genealógico, México, Editorial Santiago, 1946.

Mirafuentes Galván, José Luis, Movimientos de resistencia y rebeliones indígenas en el norte de México (1680-1821). Guía documental 1, México Universidad Nacional Autónoma de México, Instituto de Investigaciones Históricas, 1989.

Navarro García, Luis, Don José de Gálvez y la comandancia general de las provincias internas del norte de la Nueva España, Sevilla, Escuela de Estudios Hispano-Americanos, 1964.

Porras Muñoz, Guillermo, «Las minas de Chihuahua», Boletín del Archivo General de la Nación, Segunda Serie, VII, 3 (México, 1966).

Porras Muñoz, Guillermo, Iglesia y estado en Nueva Vizcaya (1562-1821), México, Universidad Nacional Autónoma de México, Instituto de Investigaciones Jurídicas, 1980.

Tracy Goode, Catherine, Corrupting the Governor: Manuel San Juan de Santa Cruz and Power in Early Eighteenth-Century Nueva Vizcaya, Thesis Masters of Arts in History, Flagstaff Northern Arizona University, 2000.

Vallebueno Garcinava, Miguel Felipe de Jesús, Cívitas y Urbs: La conformación del espacio urbano de Durango, Durango, Universidad Juárez del Estado de Durango, Instituto de Cultura del Estado de Durango, 2005.

Vargas-Lobsinger, María, Formación y decadencia de una fortuna: los mayorazgos de San Miguel de Aguayo y de San Pedro del Álamo, 1583-1823, México, Universidad Nacional Autónoma de México, Instituto de Investigaciones Históricas, 1993.

Recibido el 17 de agosto de 2009

Aprobado el 19 de noviembre de 2009

Revista de Indias, 2010, vol. LXX, n. ${ }^{\circ}$ 248, 101-126, ISSN: 0034-8341 doi:10.3989/revindias.2010.005 


\section{MANUEL SAN JUAN DE SANTA CRUZ: GOVERNOR, LARGE LANDOWNER AND ARMY CAPTAIN IN THE NORTHERN FRONTIER}

By analysing the personal papers of a powerful landowner and man-at-arms, and by examining how a large estate operated (in this case, Manuel de San Juan de Santa Cruz and the Encinillas estate), we see how the formation of these great land dominions cannot be explained only as a product of the "need for prestige» or as a simple "inclination» towards an "aristocratic way of life» on the part of their owners.

KEY words: Large estate, Indians, war, Nueva Vizcaya, estate. 